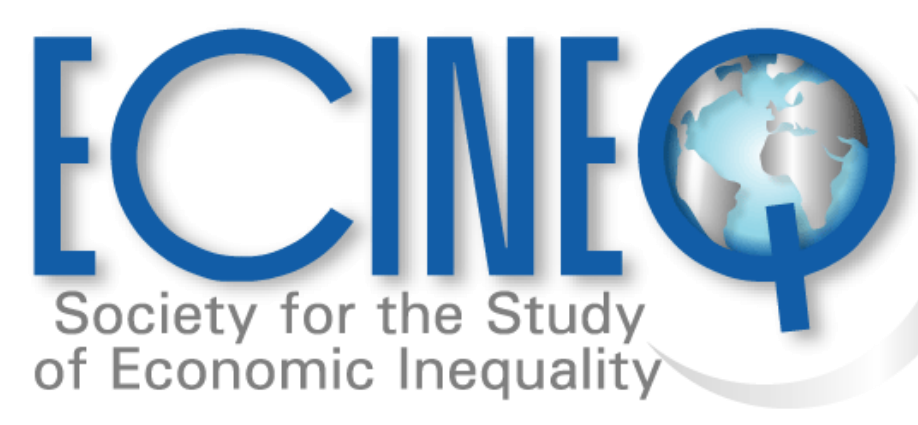

\author{
Working Paper Series
}

A New Multiplicative Decomposition For The Foster-Greer-Thorbecke Poverty Indices

Oihana Aristondo

Casilda Lasso de la Vega

Ana Urrutia 


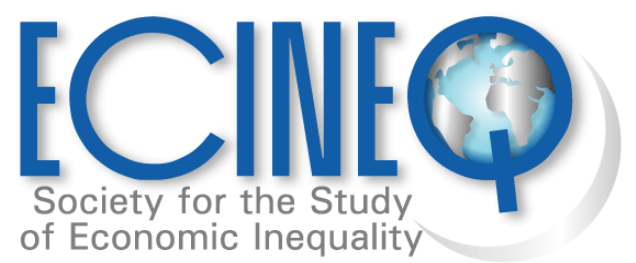

ECINEC 2008-91

August 2008

www.ecineq.org

\title{
A New Multiplicative Decomposition For The Foster-Greer-Thorbecke Poverty Indices $^{*}$
}

\author{
Oihana Aristondo \\ Casilda Lasso de la Vega \\ and Ana Urrutia ${ }^{\dagger}$ \\ University of the Basque Country. Spain
}

\begin{abstract}
This paper identifies a multiplicative decomposition for the Foster-Greer-Thorbecke poverty indices as a product of the three components which should be involved in every poverty index: the incidence of poverty, measured by the headcount ratio, the intensity of poverty, measured by the aggregate income gap ratio and the inequality among the poor measured by an increasing transformation of the corresponding inequality index of the Generalized Entropy family. Then, taking data from the Spanish Household Budget Surveys (SHB) as a basis we show the advantages and possibilities of this framework in regard to completing and detailing information in studies of poverty over time.
\end{abstract}

Key words: Poverty Measurement, Foster-Greer-Thorbecke poverty indices, Multiplicative Decomposition.

JEL Classification: I30, I32, D63

\footnotetext{
* We are grateful to P. Lambert for his detailed comments and suggestions. A preliminary version of this paper was presented in the 5th International Conference on Logic, Game Theory and Social Choice (Bilbao, 2007). We also wish to thank the participants in this conference for their suggestions and comments.

This research has been partially supported by the Spanish Ministerio de Educación y Ciencia under project SEJ2006-05455, cofunded by FEDER and by the University of the Basque Country under the projects GIU06/44 and UPV05/117.

tAddress for correspondence: Oihana Aristondo, University of the Basque Country, Department of Applied Economics IV, Av. Lehendakari Aguirre, 83, 48015-Bilbao (Spain). E-mail: oihana.aristondo@ehu.es

$\mathrm{M}^{\mathrm{a}}$ Casilda Lasso de la Vega, University of the Basque Country, Department of Applied Economics IV, Av. Lehendakari Aguirre, 83, 48015-Bilbao (Spain). E-mail: casilda.lassodelavega@ehu.es

Ana Marta Urrutia, University of the Basque Country, Department of Applied Economics IV, Av. Lehendakari Aguirre, 83, 48015-Bilbao (Spain). E-mail: anamarta.urrutia@ehhu.es
} 


\section{INTRODUCTION}

In a seminal article Sen (1976) argued that a poverty index should be sensitive to the number of people below the poverty line, to the extent of the short-fall of the income of the poor from the poverty line and to the exact pattern of distribution of the incomes of the poor. In other words, every poverty measure should be expressed as a function of these three poverty indicators, showing the incidence, the intensity and the inequality of the poverty respectively, the three 'I's of poverty according to Jenkins and Lambert's designation (1998b). When analyzing the sources of changes in poverty it is therefore of interest to ask how much of a change in poverty is due to changes in these components and to know if increasing poverty is due to more people becoming poor, or increasing deprivation of the poor, or because income short-fall below the poverty line have become more unequal, or some combination of the above. Thus, poverty changes are more meaningful and easily understandable if poverty indices can be decomposed into their underlying contributing factors. There are indices in the literature for which it is possible to know this function explicitly. Besides Clark et al. (1981) and Osberg and Xu (2000), some of them may be found in Kakwani (1999).

However, it may be interesting to note that, up to now, a decomposition in these three components is identified for only one index of the Foster, Greer and Thorbecke family (1984), henceforth FGT family. One of the characteristics of the indices of the FGT class is that they are additively decomposable. In addition, Foster and Shorrocks (1991) establish that the FGT class contains the canonical forms of one interesting family of subgroup consistent ${ }^{\ddagger}$ relative poverty indices. Moreover Foster and Shorrocks (1988a, 1988b and 1988c) prove a useful link between the FGT indices and stochastic dominance which makes the analysis of the poverty dominance easier.

In this connection it would be helpful and worthwhile to examine these measures in terms of their contributing components. Specifically in Section III this paper proves that each index in the FGT family can be viewed as a product of the headcount ratio, the aggregate income gap ratio, and an increasing transformation of the Generalized Entropy inequality index of the income gaps of the poor. A brief illustration taking data from the Spanish Household Budget Surveys (HBS) for 1973/74, 1980/81 and 1990/91 and the more recent continuous HBS for 2000 shows the possibility of this new decomposition in regard to completing and detailing information in studies of poverty over time. The notation is presented in Section II while Section V offers some concluding remarks.

\section{NOTATION}

\footnotetext{
* The subgroup consistent principle as defined by Foster and Shorrocks (1991) requires that poverty must increase when poverty increases in any subgroup without decrease in poverty elsewhere.
} 
We consider a population consisting of $n \geq 2$ individuals. Individual i's income is denoted by $y_{\mathrm{i}} \in \mathbb{R}_{++}=(0, \infty), \mathrm{i}=1,2, \ldots, n$. An income distribution is represented by a vector $\mathbf{y}=\left(\mathrm{y}_{1}, \mathrm{y}_{2}, \ldots, \mathrm{y}_{\mathrm{n}}\right) \in \mathbb{R}_{++}^{\mathrm{n}}$ arranged in increasing order. We let $\mathrm{D}=\bigcup_{\mathrm{n}=1}^{\infty} \mathbb{R}_{++}^{\mathrm{n}}$ represent the set of all finite dimensional income distributions. For any given poverty line $z \in \mathbb{R}_{++}$and distribution $\mathbf{y} \in \mathrm{D}$ we define as poor all incomes $\mathrm{y}_{\mathrm{i}} \leq \mathrm{z}_{\mathrm{z}}$. We denote by $\mathrm{n}=\mathrm{n} \mathbf{y}$ and $\mathrm{q}=\mathrm{q} \mathbf{y} ; \mathrm{z}$ the population size and the number of the poor respectively, and by $\mu(\mathbf{y})$ the mean income of $\mathbf{y}$. Let $g_{i}=z^{-} y_{i} / z$ be the income gap ratio of the $i$-th poor and $\mathbf{g}=\mathrm{g}_{1}, \ldots, \mathrm{g}_{\mathrm{q}}$ the income gap ratio vector.

Poverty indices which will be mentioned in this paper are the headcount ratio $\mathrm{H}=\mathrm{H} \mathbf{y} ; \mathrm{z}=\mathrm{q} \mathbf{y} ; \mathrm{z} / \mathrm{n} \mathbf{y} ;$ the aggregate income gap ratio $\mu_{\mathrm{g}}=\mu_{\mathrm{g}} \mathbf{y} ; \mathrm{z}=\sum_{1 \leq \mathrm{i} \leq \mathrm{q}} \mathrm{z}^{-} \mathrm{y}_{\mathrm{i}} / \mathrm{qz} ;$ the poverty gap ratio which is equal to the product of the headcount ratio and the aggregate income gap ratio, i. e. $\mathrm{H}^{\mu} \mathrm{g}$, and the FGT family proposed by Foster et al. (1984), given by

$$
\mathrm{FGT}_{\alpha} \quad \mathbf{y} ; \mathrm{z}=\frac{1}{\mathrm{n}} \sum_{\mathrm{i}=1}^{\mathrm{q}}\left(\frac{\mathrm{z}-\mathrm{y}_{\mathrm{i}}}{\mathrm{z}}\right)^{\alpha} \quad \alpha>1
$$

Particularly interesting is to note that when $\alpha=0$ the measure $\mathrm{FGT}_{0}$ is simply the headcount ratio $\mathrm{H}$ and when $\alpha=1 \mathrm{FGT}_{1}$ is the poverty gap ratio, $\mathrm{H}^{\mu} \mathrm{g}$. Moreover, Foster et al. (1984) propose a decomposition for $\mathrm{FGT}_{2}$ using the headcount ratio, the aggregate income gap ratio and the squared coefficient of variation, according to the following expression:

$$
\mathrm{FGT}_{2} \quad \mathbf{y} ; \mathrm{z}=\mathrm{H} \mu \mathrm{g}^{2}+1-\mu_{\mathrm{g}}{ }^{2} \mathrm{C}_{\mathrm{p}}^{2}
$$

where $\mathrm{C}_{\mathrm{p}}^{2}$ is the squared coefficient of variation of the poor income. 
Finally, in the following the inequality indices of Generalised Entropy class, henceforth GE class, (among others Bourguignon (1979), Shorrocks (1984), Cowell, (1980)) will play a role. The GE family is given by:

$$
I_{\alpha}^{\mathrm{GE}} \mathbf{y}=\left\{\begin{array}{cc}
\sum_{1 \leq \mathrm{i} \leq \mathrm{n}} \mathrm{y}_{\mathrm{i}} / \mu^{\alpha}-1 / \mathrm{n} \alpha^{2}-\alpha & \alpha \neq 0,1 \\
-\sum_{1 \leq_{\mathrm{i}} \leq_{\mathrm{n}}} \log \mathrm{y}_{\mathrm{i}} / \mu / \mathrm{n} & \alpha=0 \\
\sum_{1 \leq_{\mathrm{i}} \leq_{\mathrm{n}}} \mathrm{y}_{\mathrm{i}} / \mu \log \mathrm{y}_{\mathrm{i}} / \mu / \mathrm{n} & \alpha=1
\end{array}\right.
$$

\section{THE THREE ‘I’S OF POVERTY IN THE FGT FAMILY}

Since Sen (1976) any poverty index can be expressed as

$$
\mathrm{P}=\phi \quad \mathrm{H}, \mu_{\mathrm{g}, \mathrm{I}}
$$

where $\mathrm{H}$ is the headcount ratio, considered as the archetypical measure of the incidence of poverty, $\mu_{\mathrm{g}}$ is the aggregate income gap ratio, measuring the intensity of poverty ${ }^{\S}$ and I captures inequality among the poor and $\phi$ is a non-decreasing function in its arguments. The proposition below shows that every FGT index allows a multiplicative decomposition in these three terms With respect to the inequality of the poor, which can be equivalently measured in terms of either income or gaps of the poor, in the decomposition we propose, an index of the GE class, measuring inequality of the income gap ratios of the poor, is involved.

Proposition 1: For each $\alpha>1, F G T_{\alpha} \mathbf{y} ; z$ satisfies the following multiplicative decomposition:

$$
F G T_{\alpha} \quad \mathbf{y} ; z=H \quad \mathbf{y} ; z \quad \mu_{g} \quad \mathbf{y} ; z^{\alpha}{ }^{\alpha} 1+\alpha^{2}-\alpha \quad I_{\alpha}^{G E} \mathbf{g}
$$

Proof. The proof is straightforward after a few lines of standard computations and rearrangements.

Q.E.D.

\footnotetext{
$\S$ The poverty gap ratio is also used to measure intensity of poverty (Jenkins and Lambert (1998a, 1998b) for instance).
} 
This proposition shows that each FGT ${ }_{\alpha}$ poverty index can be decomposed in a very simple way just as the product of the headcount ratio, the aggregate income gap ratio to the power of $\alpha$ and one plus the corresponding GE inequality index of vector of the income gap ratios of the poor multiplied by $\alpha^{2}-\alpha$. As is well known, for large positive parameter values the GE index is sensitive to what happens to high values of the distribution, in this case to large values of income gap ratios, therefore to the poorest of the poor.

The simplicity of this decomposition is the major difference as regards previous decomposition formulae for various poverty measures displayed by Kakwani (1999). This simplicity is shared by the decomposition of the Sen poverty index proposed by Clark et al. (1981) and that of the Sen-Shorrocks-Thon poverty index proposed by Osberg and Xu (2000).

As usual, the multiplicative decomposition in (4) is a starting point for the derivation of the impact of marginal changes in a given component on overall poverty. Indeed the multiplicative decomposition of these indices can be transformed, through the logarithmic transformation, so that it is additive in a simple form. The marginal effects derived from multiplicative decomposition appear in the following equation

$$
\Delta \mathrm{FGT}_{\alpha}=\Delta \mathrm{H}+\Delta\left(\mu_{\mathrm{g}}\right)^{\alpha}+\Delta \mathrm{I}_{\alpha}^{*}
$$

where $I_{\alpha}^{*}=1+\alpha^{2}-\alpha \underset{\alpha}{\mathrm{GE}} \mathbf{g}$, and in general $\Delta \mathrm{x}=\ln \mathrm{x}_{\mathrm{t}}-\ln \mathrm{x}_{\mathrm{t}-1} \approx\left(\mathrm{x}_{\mathrm{t}}-\mathrm{x}_{\mathrm{t}-1}\right) / \mathrm{x}_{\mathrm{t}-1}$ approximates the percentage rate of change in $\mathrm{x}$.

This equation shows that the overall percentage rate of change in poverty can be expressed as the sum of the percentage rate of changes in the headcount ratio, the aggregate income gap ratio and inequality of the income gap ratios of the poor, and allows us to determine if increasing poverty is due to either more people becoming poor, or increasing deprivation of the poor, or because income short-falls below the poverty line have become more unequal, or some combination of the above.

\section{AN EMPIRICAL ILUSTRATION}

The methodology developed in this paper will now be illustrated with data from Spanish Household Budget Surveys (HBS) for 1973/74, 1980/81 and 1990/91 and the continuous 
HBS for $2000^{* *}$. The variable we use is the net expenditure per capita ${ }^{\dagger \dagger}$ and the poverty line is $50 \%$ of the mean income of each year. Although statistical analysis with explicit confidence intervals is desirable to gauge to what extent measured changes correspond to real changes, an analysis of that kind is beyond the scope of this brief note.

Taking into account, as already mentioned, that FGT ${ }_{0}$ is the headcount ratio, i.e. $\mathrm{H}$, and FGT $_{1}$, is the poverty gap ratio, i.e. $\mathrm{H} \mu_{\mathrm{g}}$, we decompose $\mathrm{FGT}{ }_{2}$ and FGT ${ }_{3}$ into incidence, $\mathrm{H}$, intensity, $\mu_{\mathrm{g}}$, and inequality as measured by $\mathrm{I}_{2}^{\mathrm{GE}}$ and $\mathrm{I}_{3}^{\mathrm{GE}}$ respectively.

TABLE 1

The three 'I's in $F G T_{0}, F G T_{1}, F G T_{2}$ and $F G T_{3}$.

\begin{tabular}{cccccccc}
\hline & $\mathbf{F G T}_{\mathbf{0}}=\mathbf{H}$ & $\mathbf{F G T}_{\mathbf{1}}=\mathbf{H} * \boldsymbol{\mu}_{\mathrm{g}}$ & $\mathbf{F G T}_{\mathbf{2}}$ & $\mathbf{F G T}_{\mathbf{3}}$ & $\boldsymbol{\mu}_{\mathrm{g}}$ & $\mathbf{I}_{\mathbf{2}}^{\mathbf{G E}}$ & $\mathbf{I}_{\mathbf{3}}^{\mathbf{G E}}$ \\
\hline $\mathbf{1 9 7 3}$ & $20.1 \%$ & 0.054 & 0.022 & 0.011 & 0.27 & 1484 & 2649 \\
$\mathbf{1 9 8 0}$ & $19.1 \%$ & 0.052 & 0.021 & 0.010 & 0.271 & 1503 & 2761 \\
$\mathbf{1 9 9 0}$ & $17.3 \%$ & 0.042 & 0.016 & 0.007 & 0.241 & 1544 & 2968 \\
$\mathbf{2 0 0 0}$ & $13.4 \%$ & 0.031 & 0.011 & 0.005 & 0.23 & 1569 & 3083 \\
\hline
\end{tabular}

As can be seen in Table $1 \mathrm{FGT}_{0}, \mathrm{FGT}_{1}, \mathrm{FGT}_{2}$ and $\mathrm{FGT}_{3}$ show monotonic reductions in this period. Indeed, the percentage of poor has decreased from $20.2 \%$ in 1973 to $13.4 \%$ in 2000 and the poverty gap ratio, $\mathrm{FGT}_{1}$, has also decreased from 0.054 to 0.031 . A similar pattern emerges when we measure poverty by $\mathrm{FGT}_{2}$ and $\mathrm{FGT}_{3}$. The inequality components corresponding to both $\mathrm{FGT}_{2}$ and $\mathrm{FGT}_{3}$ have increased, but not by enough to reverse the downward overall trends.

TABLE 2

Decomposition of poverty trend.

Contribution to the change in poverty as measured by $\mathrm{FGT}_{2}$

\begin{tabular}{lcccc}
\hline & $\mathbf{F G T}_{\mathbf{0}}=\mathbf{H}$ & $\left(\boldsymbol{\mu}_{\mathrm{g}}\right)^{\mathbf{2}}$ & $\mathbf{I}_{\boldsymbol{}_{\mathbf{2}}}$ & total \\
\hline $\mathbf{1 9 7 3}$ to $\mathbf{1 9 8 0}$ & -5.1 & 0.7 & 1.3 & -3.4 \\
$\mathbf{1 9 8 1}$ to $\mathbf{1 9 9 0}$ & -9.9 & -23.5 & 2.7 & -30.1 \\
$\mathbf{1 9 9 1}$ to 2000 & -25.5 & -9.3 & 1.6 & -33.9 \\
\hline $\mathbf{1 9 7 3}$ to $\mathbf{2 0 0 0}$ & -40.5 & -32.1 & 5.6 & -67.5 \\
\hline
\end{tabular}

Contribution to the change in poverty as measured by $\mathrm{FGT}_{3}$

\begin{tabular}{cccc}
\hline $\mathbf{F G T}_{\mathbf{0}}=\mathbf{H}$ & $\left(\boldsymbol{\mu}_{\mathrm{g}}\right)^{\mathbf{3}}$ & $\mathbf{I}_{\mathbf{3}}$ & total \\
\hline-5.1 & 1.1 & 4.1 & -0.2 \\
-9.9 & -35.2 & 7.2 & -37.2 \\
-25.5 & -14 & 3.8 & -36.3 \\
\hline-40.5 & -48.1 & 15.2 & -73.7 \\
\hline
\end{tabular}

\footnotetext{
** An in-depth study of the evolution of poverty in Spain in the same period has been carried out by del Río and Ruiz-Castillo (2001) applying the methodology developed by Jenkins and Lambert (1998a, 1998b).

$\dagger$ The results are basically the same if another equivalence of scale is used.
} 
Using equation (5), Table 2 offers a decomposition of the poverty trend into the contributions associated with these three components, for the index $\mathrm{FGT}_{2}$ (analogous results can be obtained by analysing $\mathrm{FGT}_{3}$ ).

First of all it is noteworthy that the decline in the headcount has decreased the poverty rate by 40.5 percentage points over the period 1980-2000. Decreasing the poverty gap ratio has contributed a further 32 points, while a higher inequality has caused the poverty change to increase by 5.6 points. The conclusion that follows from these results is that the decline in poverty by 67.4 percentage points over the whole period is due mainly to the declines in the headcount and in the poverty gap ratios.

If we look at the results decade by decade, we can see that the main sources of the poverty changes are not the same. In fact, in the periods 1980-90 and 1990-2000 the poverty decrease displays similar values although the origins of these reductions are quite different. The principal cause of lower poverty in 1980-90 was the decrease in the poverty gap ratio, whereas in the 1990-2000 it was the decline in the headcount ratio. It is the new decomposition (4) and the breakdown into impacts (5), which enable these insights.

\section{CONCLUDING REMARKS}

This paper proposes a new decomposition for the FGT poverty indices allowing us to better understand the underlying structure of this family and to analyse sources of poverty change. It would be of interest to explore a unified framework for the study of changes in poverty over time establishing a connection between this procedure and the recent pro-poor growth literature in order to decompose the change in poverty into growth and inequality effects. This is an important issue for further research.

\section{REFERENCES}

Bourguignon, F., 1979, Decomposable income inequality measures, Econometrica, 47, 901920.

Clark, S., R. Hemming and D. Ulph, 1981, On indices for the measurement of poverty, Economic Journal, 91, 515-26. 
Cowell, F. A., 1980, On the structure of additive inequality measures, Review of Economic Studies, 47, 521-31.

del Río C. and J. Ruíz-Castillo, 2001, TIPs for poverty analysis. The case of Spain. 1980-81 to 1990-91, Investigaciones Económicas, vol. XXV (1), 63-91.

Foster, J., J. Greer and E. Thorbecke, 1984, A class of decomposable poverty measures, Econometrica, 52, 761-766.

Foster, J. and A. Shorrocks, 1988a, Poverty Orderings, Econometrica, 56, 173-177.

Foster, J. and A. Shorrocks, 1988b, Poverty Orderings and Welfare Dominance, Social Choice and Welfare, 5, 179-198.

Foster, J. and A. Shorrocks, 1988c, Inequality and Poverty Orderings, European Economic Review, 32, 654-662.

Foster, J. and A. Shorrocks, 1991, Subgroup consistent poverty indices, Econometrica, 59, 687-709.

Jenkins, S. and P. Lambert, 1998a, Ranking poverty gap distributions: further TIPs for poverty analysis. Research on Economic Inequality 8, (JAI Press, Greenwich), 31-38

Jenkins, S. and P. Lambert, 1998b, Three 'I's of poverty curves and poverty dominance: TIPs for poverty analysis, Research on Economic Inequality 8, (JAI Press, Greenwich), $39-56$

Kakwani, N., 1999, Inequality, Welfare and Poverty, in J. Silber, eds., Handbook of income inequality measurement, (Kluwer Academic Publishers, Massachusetts), 599-628.

Seidl, C., 1988, Poverty Measurement: A Survey, in D. Bös, M. Rose and C. Seild, eds., Welfare and Efficiency in Public Economics, (Springer-Verlag, Berlin).

Sen, A. K., 1976, Poverty: An Ordinal Approach to Measurement, Econometrica, 44, 219231.

Shorrocks, A. F., 1984, Inequality decomposition by population subgroups, Econometrica, $52,1369-1385$.

Osberg, L. and $\mathrm{K} . \mathrm{Xu}, 2000$, International comparisons of poverty intensity: Index decomposition and bootstrap inference, The Journal of Human Resources, XXXV, 1-81 